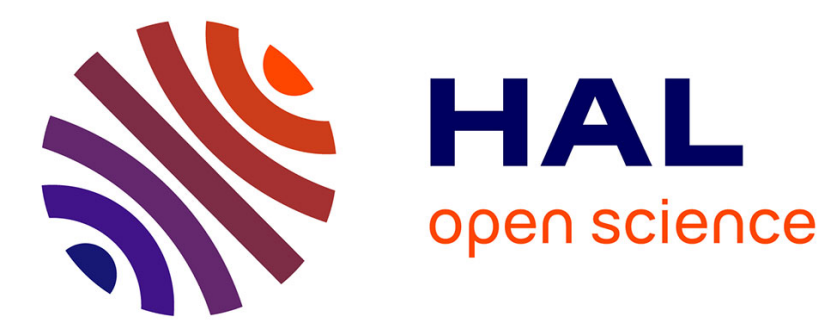

\title{
Smart City for Development: A Conceptual Model for Developing Countries
}

\author{
Luiz Antonio Joia, Alexander Kuhl
}

\section{To cite this version:}

Luiz Antonio Joia, Alexander Kuhl. Smart City for Development: A Conceptual Model for Developing Countries. 15th International Conference on Social Implications of Computers in Developing Countries (ICT4D), May 2019, Dar es Salaam, Tanzania. pp.203-214, 10.1007/978-3-030-19115-3_17 . hal02281315

\section{HAL Id: hal-02281315 \\ https://hal.inria.fr/hal-02281315}

Submitted on 9 Sep 2019

HAL is a multi-disciplinary open access archive for the deposit and dissemination of scientific research documents, whether they are published or not. The documents may come from teaching and research institutions in France or abroad, or from public or private research centers.
L'archive ouverte pluridisciplinaire HAL, est destinée au dépôt et à la diffusion de documents scientifiques de niveau recherche, publiés ou non, émanant des établissements d'enseignement et de recherche français ou étrangers, des laboratoires publics ou privés. 


\title{
Smart City for Development: A conceptual model for developing countries
}

\author{
Luiz Antonio Joia ${ }^{1[0000-0002-5903-5190]}$ and Alexander Kuhl ${ }^{1[0000-0002-9734-2597]}$ \\ ${ }^{1}$ Getulio Vargas Foundation, Rio de Janeiro RJ 22231-010, Brazil \\ Luiz.joia@fgv.br
}

\begin{abstract}
The present article addresses how smart city initiatives can positively impact development, with a special emphasis on developing countries. Extant definitions and maturity models on smart cities have a very strong focus on the mere use of Information and Communication Technology (ICT), thereby ignoring the special needs and factors to be considered in developing countries. Thus, by using the extant literature on Smart Cities and Information and Communication Technology for Development (ICT4D), a comprehensive Smart City for Development (SC4D) model is introduced. The article argues that a favorable ecosystem for SC4D is one that is backed by both national and local sustainability, infrastructure, human capital, services, apps, and data. Moreover, successful SC4D initiatives include bottom-up approaches, citizen participation, a fit with both the national and the local culture, as well as a fit with the United Nations' Sustainable Development Goals and the Capability Approach.
\end{abstract}

Keywords: ICT4D, Smart City, Capability Approach

\section{Introduction}

While the study field of ICT has been receiving increased attention and significance throughout the past few decades, the conventional wisdom has become that, if they are conducted efficiently, ICT projects in the public sector enable citizens to access services of higher efficiency [8]. In developed countries, this translates into increased productivity, whereas in developing countries the impact of ICT4D is far more meaningful and may, for instance, help eradicate poverty, handle problems related to climate change or enable people's inclusion in economic, social and political life [20].

Recently, a topic closely related to ICT and ICT4D has emerged: the idea of making cities smarter to take advantage of the benefits of the digital age. As of 2012, there were around 143 self-declared smart city projects worldwide, most of which were located in Europe, North America and Asia [31]. These numbers show that the relevance and existence of smart city initiatives are higher in developed than in developing countries. Yet, at the same time, smart cities have a lot of potential to foster sustainable development in developing countries - a potential that is not being completely achieved so far - and worse, structural problems might even extend the gap between this potential and the reality [15].

In that context, the present paper aims to provide a framework that may support developing countries policymakers to recognize the potential of smart city initiatives to foster development in their respective developing country.

Thus, this article addresses the following research question: How can smart city initiatives impact development in developing countries? 


\section{Methodological Procedures}

The methodology supporting this article involves three main research stages, namely:

1. Literature review: to identify and discuss the most significant research literature that treats ICT4D and the smart city knowledge fields;

2. Model development: built upon the knowledge taken from the literature review, a vision for SC4D and its conceptual framework are determined. Then, considering this vision, the structure of a conceptual framework for SC4D is created. This model aims to guide how smart city initiatives in developing countries must be designed by governments and supported by ecosystems in order to lead to the desired positive impact on development.

3. Synthesis: implications for public policies accrued from this work.

\section{Literature Review}

\subsection{ICT for development (ICT4D)}

The United Nations Economic and Social Council emphasizes the potential impact on the social and economic development of a country related to ICTs that, if applied in a strategic manner, can lead to increasing growth, create income sources for poor people and reduce poverty [48]. In addition to such social and economic aspects, the European Parliament mentions the possibility of better outcomes in the areas of healthcare and education for developing countries that make use of ICTs [16]. Thus, in a wider sense, ICT4D endeavors intend to harness digital technologies in the service of the world's most pressing problems, addressing the needs of the poor [20]. In regard to the latter, it is argued that ICT4D initiatives should be inclusive including the poor in improved services and opportunities -, enabling - supporting policies that improve the lives of the poor - and focused - aiming at the poor's rights, interests, and needs -, yet at the same time sustainable, scalable and effective [35].

While ICT initiatives have in the past mainly focused on tangible benefits of ICTs that are easily measurable and quantifiable, there was a shift in that focus towards intangible benefits, such as empowerment, self-esteem, and social cohesion, since these are more important from a developmental perspective [19].

A similar approach to the evaluation of ICT4D initiatives is offered by [29], who argues that instead of trying to make ICTs fit with a linear conceptualization of impacts and an often economistic view of development, an ICT4D endeavor is a development process that needs to be analyzed in a holistic way based on Amartya Sen's capability approach. Development should be seen from the perspective of individual freedom rather than as mere economic growth $[41,42,43]$. In this context, capabilities are factors that determine the freedom of choice regarding the question of how to live one's life. They are therefore the central element to consider in the assessment of human development.

Eventually, the application of the capability approach to ICT4D has not only remained an academic idea but also been put into practice, for instance, with regard to the World Bank's development strategy: instead of solely considering new 
technologies and the introduction of such, the focus of ICT4D projects increasingly lies on people and on how a meaningful use of ICTs enhances both the individual human capabilities and the collective social capabilities inside a community [18].This focus on the people should also be considered in the initial design of ICT4D initiatives and the way in which they are directed: while top-down approaches may be necessary to create a favorable environment for the use and diffusion of ICTs, there is a need for more and innovative bottom-up approaches, since it is crucial to include and empower local stakeholders in order to create ICT4D projects that are actually sustainable [37]..

\subsection{Digital inclusion}

Digital inclusion means to provide opportunities for people to be included in the current digital society [14]. Yet, merely making ICTs available is not enough and the political, social, cultural and institutional environment needs also to be taken into account, since these are factors that influence the access to ICTs and the ability to make effective use of them [49]. In this context, [26,27] provides a model that includes the key success factors and processes that should underlie the promotion of digital inclusion in a country (Figure 1).

\section{The Virtuous Empowerment and Participation Cycle}

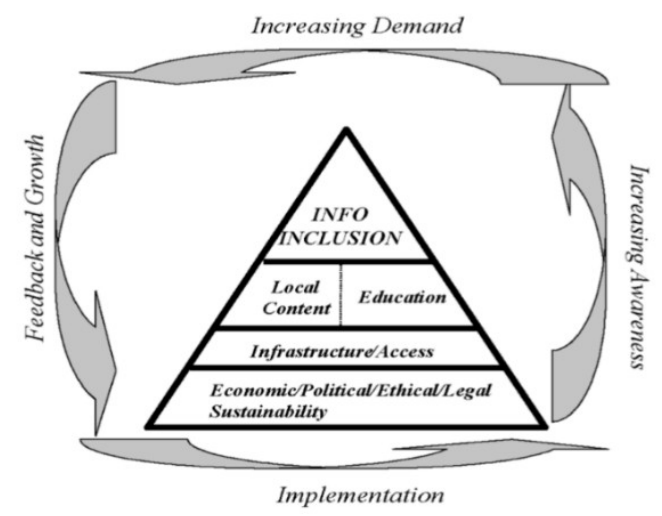

Fig. 1: The Dynamic Infoinclusion Model [25]

According to that model, the primary requirement is economic, political, ethical and legal sustainability, meaning that the government's actions need to support a favorable ecosystem. Secondly, infrastructure and access need to be made available. Thirdly, local content and education must be provided, being same relevant and customized for the needs and interests of the local community or target group with the particular objective of empowering socially excluded groups. Lastly, the model emphasizes the digital inclusion as a dynamic process. Thus, the model features a socalled virtuous participation and empowerment cycle that includes four stages: at the first stage, an ICT initiative and corresponding tools are implemented; subsequently, at the second stage, people become increasingly aware of the possibilities and benefits connected to these tools; this ought to lead to the third stage, in which current 
participants increase their demand for the implementation of further tools, applications and IT infrastructure in general; consequently, at a fourth stage, those people that are already included in the process give feedback on it and, at the same time, have a feeling of involvement and empowerment, while the number of new users grows as well [45].

\subsection{Smart cities}

According to the United Nations, nowadays the resources and energy consumption of cities are dramatically high [46]. Moreover, while more than $50 \%$ of people worldwide were already living in urban areas by 2008, this figure is expected to further rise to $70 \%$ by 2050 ; in Europe, about $80 \%$ of people are already living in urban areas, and both the mentioned changes and their impacts are going to be much more significant in regions such as Asia, Latin America, and Africa, where the diffusion of megacities of more than 20 million people is already a reality [46].

In light of this, cities worldwide are required to become "smart", or in other words, to find intelligent and innovative ways to tackle the upcoming challenges effectively $[9,33]$. However, the definition and purpose of a so-called smart city have led to controversy in Academia, having a variety of proposals on this matter [2]. In fact, there is no one-size-fits-all definition, neither for the smart city term nor for the successful conceptualization of a smart city [36]. What is noteworthy is that while at the beginning, most of the definitions of smart city had a very strong focus on the diffusion of ICTs and tended to disregard the importance of other crucial factors besides technology, recent approaches have shifted towards the needs of people and communities [2], such as the quality of life [4]. Indeed, it is important to acknowledge that within the concept of successfully creating a smart city, ICTs are just one thread in the system as the deployment of such must follow an integrative and multidimensional approach [40]. In a truly smart city, adopting new technologies is not an end in itself as innovation in technology must be complemented by innovation in management and policy [34]. Besides, progressive smart city initiatives must start with the focus on human capital - people, their interaction, knowledge, skills, and participation - rather than with the blind belief that ICTs can automatically transform and improve cities [23]. Thus, some authors developed one of the most recent approaches for a unified definition of a smart city and came to the result that there are 25200 potential components of a smart city: the more components a city is composed of, the smarter it is [39].

\section{The Vision for a Smart City for Development Model (SC4D)}

As the concept of ICT4D was introduced in order to customize the concept of ICT diffusion to lead to a positive impact on development in developing countries [20, the idea behind the concept of SC4D envisioned by the present article is to adapt the concept of smart cities in order to create customized smart city solutions with the objective of positively impacting development in developing countries. This customization is important because responses to challenges in cities inside developing countries will need to be tailored and framed differently from those in cities inside 
developed countries, due to the fact that urban growth will be a bigger phenomenon and therefore a more present problem in the developing world [46]. Because of this and against the background of the vague and broad conceptualization of smart cities [39], it is first necessary to redefine and narrow down the term to make it appropriate for developing countries.

Due to its focus on development, a feasible definition might be one that has been introduced by the Inter-American Development Bank (IDB) [7]. According to that definition, a smart city is an innovative city that uses a holistic approach - including both ICTs and other means - in order to improve the quality of life, efficiency of urban operations and services, as well as competitiveness, while ensuring that it fulfils both present and future generations' needs related to economic, social, urban and environmental factors, thus placing people at the center and implementing collaborative planning activities and citizen participation methods.

Yet, if the question is how smart cities can foster development, the term of development itself needs to be defined as well. The inspiration for this can be found within the process that the ICT4D movement has gone through: after initially focusing too much on technology, an increased shift towards other factors took place over time. Within the context of smart city initiatives in developing countries, this means viewing development as freedom [43] in a city context, such as an increase in a city's citizens' well-being, as well as in their capabilities [18,42] - capabilities meaning the different ways of living a life that are possible to be achieved and freely chosen [29]. A shift towards SC4D also means acknowledging the significance of intangible benefits of smart city initiatives, such as empowerment, social cohesion, and self-esteem, as done for ICT4D [19]. The focus on bottom-up approaches [38] and the society's poorest [35] should be further points, in which the modern approach within ICT4D may serve as a role model for the conceptualization of SC4D. With regard to the latter suggestion - targeting the society's poorest - the vision of SC4D suggested in the present article is that instead of improving the lives of those citizens that are already highly privileged, relevant SC4D initiatives should aim at targeting those people that are most in need, namely the world's four billion poorest people with an income that is too low to sustain a decent life [38]. Moreover, an additional guideline can be the Sustainable Development Goals (SDGs), which have been declared by the United Nations (UN) and include "no poverty", "zero hunger", "good health and well-being”, "quality education", "gender equality", "clean water and sanitation", "affordable and clean energy", "decent work and economic growth", "industry, innovation and infrastructure", "reduced inequalities", "sustainable cities and communities", "responsible consumption and production", "climate action", "life below water", "life on land", "peace, justice and strong institutions" and "partnership for the goals" as facets of development [47].

In summary, any smart city initiative that targets the underprivileged citizens of any city inside any developing country, improves their quality of life, enhances their capabilities, and significantly and positively contributes to one or more of the 17 SDGs, is a smart city initiative that fosters development and may therefore be considered a successful SC4D initiative. 


\subsection{The SC4D model underlying rationale}

Considering the implications from the literature review and the defined vision for SC4D on the basis of ICT4D, a framework that effectively describes the nature and ecosystem of successful developing countries SC4D initiatives needs to comprehensively involve the success factors already discussed, be a dynamic model [25], involve participation [37], focus on development and capabilities $[18,19,29,35,487$ and also factor the indigenous contextual or cultural component in. Besides, the model should be based on academic rather than anecdotal, practitioneroriented reasoning.

None of the extant smart city assessment models is able to fulfill all of the necessary characteristics that have been defined before [1,10,12,42,47]. Thus, the rationale for developing the SC4D model is based on the need of a very dynamic model that balances ICTs with other crucial factors and has a high level of visualization, comprehensiveness, development focus and academic background.

\subsection{The SC4D model}

Based on the literature review and the vision for SC4D and taking the rationale for developing a new model into consideration, the SD4D model has been developed and is depicted below in Figure 2. Most of the model's components, especially the empowerment and participation cycle surrounding the pyramid, have been inspired by the digital inclusion model introduced by [25,27], due to its comprehensiveness and dynamic nature. However, some elements have been adapted or added with regard to the topic of smart cities. Besides, the research areas of ICT4D and digital inclusion, as closely related to the research area of smart cities, served as sources of information for the development of the SC4D model. Thus, all of the SC4D model's constituent components are further explained in the upcoming section.

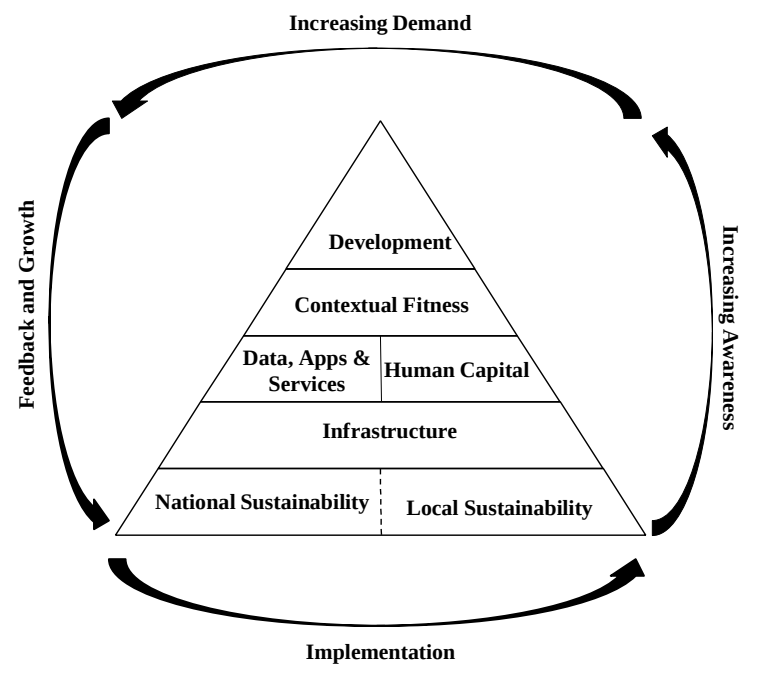

Fig 2. The SC4D Model 


\subsection{The components of the SC4D model}

\section{Sustainability}

An economic, political, ethical and legal sustainability is fundamental to a successful development project in the areas of ICT and digital inclusion [25]. Nevertheless, there are different understandings of what sustainability actually means. In a developmental context, it is understood as meeting the needs of the present without compromising future generations' ability to meet their needs, or more basically, something is sustainable if it is capable of being sustained [5]. Applying the latter definition to the before mentioned areas that need sustainability, an SC4D initiative requires a stable economy and a predictable political setting, as well as a legal system and ethical values that are coherent with the well-functioning of the project. This also implies that the situation in terms of sustainability might differ from city to city. Thus, in the assessment of a smart city project, both national and local sustainability play a role. Past failures of ICT4D initiatives have taught that a short-term focus on the initial investment can be fatal and instead, project managers must consider the sustainable viability of the respective initiative [30]. Apart from the financial aspect, a sustainable effect of ICT implementation can only be achieved if the ICT initiative also encompasses the creation of economic, social, political and cultural capabilities [18].

Accordingly, among the leading questions for the assessment of an SC4D initiative regarding this component must be:

- How economically, politically, ethically and legally sustainable is the country?

- How economically, politically, ethically and legally sustainable are the city and its region?

\section{Infrastructure}

This component addresses the ICT infrastructure, including available high-quality, high-security and privacy-ensuring wireless infrastructure and service-oriented information systems [9]. The implementation of ICT infrastructure may lead to economic growth and development and thus significantly contribute to the eradication of poverty [6]. Simultaneously, it gives low-income people the opportunity to partake in the digital society and to profit from it both economically and socially [12]. Thus, ICT infrastructure and access potentially offer the chance to increase citizens' levels of choice and are therefore of crucial value from a capability approach point of view [29]. After all, infrastructure is a key input inside any ICT4D value chain and a necessary element to ensure the readiness for ICT4D projects [21].

Accordingly, among the leading questions for the assessment of an SC4D initiative regarding this component must be:

- How developed is the city's ICT infrastructure?

- Is the ICT infrastructure sufficiently developed for a smooth functioning of the smart city project? 


\section{Data, apps, and services}

The significance of data for smart cities has been made clear in several of the extant smart city assessment models: a smart city should aim at achieving an ever more sophisticated and comprehensive [13] as well as centralized data analytics system [10]. And though highly developed data systems are more common in highly developed countries and cities, an effective usage and processing of available data is also a precursor [21] and likely to have a positive impact on SC4D initiatives. Indeed, advanced data systems should be complemented by apps and services for citizens. Modern and digital services that target the poor underlie the idea of inclusive innovation [22], which translates into the use of digital services to empower same the core of the vision for SC4D.

Accordingly, among the leading questions for the assessment of an SC4D initiative regarding this component must be:

- How developed is the city in terms of data collection, integration and centralization?

- Are there services that facilitate citizen engagement with smart city initiatives?

- $\quad$ Does the local government support smart city initiatives through apps?

\section{Human capital}

By definition, human capital comprises people's education, skills, competencies, and knowledge [28]. One emphasizes the importance of education within the context of digital inclusion, underlining however that education involves more than simply training the citizens and should be considered as more important than ICTs themselves [25]. Accordingly, the objective is that people become aware of the opportunities offered by ICTs or, in the present case, SC4D initiatives. A lack of skills and knowledge, however, might prevent any development initiative from achieving its purpose of inclusion [22]. One emphasizes other factors related to human capital apart from education, such as participation, quality of life and accessibility of ICTs for everyone [9]. Besides, what can be learned from ICT4D initiatives is that educating people about the initiative and its possible benefits for them is even more important than providing ICT infrastructure and access itself [17]. Relating this to the concept of SC4D, for a successful SC4D initiative, citizens need to be sufficiently educated and know about the opportunities the SC4D initiative brings about, while users should be skilled and competent enough.

Accordingly, among the leading questions for the assessment of an SC4D initiative regarding this component must be:

- How developed is the city in terms of human capital?

- Is the level of education in the city sufficient for a successful smart city initiative?

- What kind of training is offered in order to enable people to engage with the smart city initiative? 


\section{Contextual fitness}

The importance of respect for the local context has been emphasized before with regard to digital inclusion [25]. The same is valid for SC4D initiatives: those projects that are in line with the indigenous culture are more likely to be widely accepted and spread among the community. An example for this can be taken from the area of ICT4D: one found that in certain communities, certain individuals have influence and therefore play a decisive role during the process of popularizing innovative digital technologies [3]. There are several ways how ICTs and culture are intertwined: culture has an impact on the way ICTs are developed, adopted, diffused, used and managed, as well as on their outcomes, which may lead to vision, system or contribution conflicts [32]. Thus, the conclusion with regard to SC4D projects is that what works well in some cultural areas might not necessarily be appropriate for developing countries and what is in line with one city's local context is not necessarily applicable to all cities in the respective country.

Accordingly, among the leading questions for the assessment of an SC4D initiative regarding this component must be:

- Is the SC4D initiative compatible with the national indigenous context?

- Is the SC4D initiative compatible with the local indigenous context?

\section{Development}

This component of the SC4D model is the most important one, on the top of the pyramid. Development is the objective behind the concept of SC4D and all other components within the pyramid are supporting ones. The development component derives directly from the vision for SC4D. This vision is defined by three main ideas of development. Firstly, any SC4D initiative should work towards one or more of the SDGs [47]. In this context, the International Telecommunications Union [24] gives concrete examples regarding each of the 17 goals for ICT4D projects that had a significant and positive impact on development. Secondly, development means increasing people's capabilities and freedom [41,42,43]. The choice framework [29] involves a successful example taken from the area of ICT4D and serves as a role model for what an SC4D initiative needs to take into account to meet this second requirement. Thirdly, development means focusing especially on those people at the BOP [38].

Accordingly, among the leading questions for the assessment of an SC4D initiative regarding this component must be:

- $\quad$ Does the SC4D initiative contribute to the fulfillment of the SDGs?

- $\quad$ Does the SC4D initiative improve people's capabilities and levels of choice?

\section{Empowerment and participation cycle}

The dynamic way in which the SC4D model respects the integration of citizens in SC4D initiatives is one of its main differentiating factors compared to formerly developed assessment models for smart cities. This dynamic approach is adopted 
from [25] and - adapted here to the concept of SC4D - means that after the government implements an SC4D initiative, the targeted citizens should become aware of the initiative and the benefits for them related to it. They start giving feedback and feel involved and empowered by the SC4D initiative, consequently engaging more and demanding for an expansion of the SC4D initiative, while the total number of engaged citizens grows as well. It is expected that the government and project managers react and interact appropriately. Indeed, three of the stages of the virtuous cycle of empowerment and participation - increased awareness, increased demand, and feedback and growth - can be seen as capabilities inside the whole SC4D system [27]. When it comes to citizens' freedom and their opportunities of choosing on how to live their lives [29,41,42,43], said components of the pyramidal SC4D model have a direct and positive effect. At the same time, there is a direct link between the background of the empowerment and participation cycle and development.

Accordingly, among the leading questions for the assessment of an SC4D initiative regarding this component must be:

- Up to which extent does the SC4D initiative include bottom-up elements?

- Does the government take measures in order to increase people's awareness and demand?

- Is the initiative open to receiving and implementing citizens' feedback?

\section{Conclusions}

The SC4D model might be a helpful tool for governments and smart city project managers in developing countries to implement and/or evaluate SC4D initiatives. Governments might use this model because it offers a holistic approach that balances ICT with other needs. Smart cities have in a recent past been established with a bias towards the mere diffusion of ICTs. Yet, the SC4D model changes the focus towards further components, such as sustainability, infrastructure, data, apps, services, human capital, cultural and contextual fitness, and citizen empowerment and participation. Thus, governments of cities in developing countries might adapt their smart city endeavors accordingly in order to ensure that same are successful, targeting people most in need.

\section{References}

1. Afonso, R. A., Brito, K. d., Nascimento, C. H., Garcia, V. C., \& Álvaro, A. (2015). Brazilian Smart Cities: Using a Maturity Model to Measure and Compare Inequality in Cities.

2. Albino, V., Berardi, U., \& Dangelico, R. M. (2015). Smart Cities: Definitions, Dimensions, Performance, and Initiatives. Journal of Urban Technology, 22(1), 3-21.

3. Andrade, A. D., \& Urquhart, C. (2009). Mavericks, mavens and social connectors: computer-mediated information seeking behaviour in rural societies. International Conference on Social Implications of Computers in Developing Countries. Dubai.

4. Batty, M., Axhausen, K. W., Giannotti, F., Pozdnoukhov, A., Bazzani, A., Wachowicz, M., . . . Portugali, Y. (2012). Smart cities of the future. The European Physical Journal Special Topics, 214, 481 - 518. 
5. Beaumont, P. (2013, June 5). 5 Definitions of Sustainability. Retrieved from http:// blogs.rochester.edu/thegreendandelion/2013/06/5-definitions-of-sustainability/

6. Beuermann, D. W. (2018). Mobile Phones and Economic Development in Rural Peru. 48(11).

7. Bouskela, M., Casseb, M., Bassi, S., Luca, C. D., \& Facchina, M. (2016). The Road toward Smart Cities: Migrating from Traditional City Management to the Smart City. Inter-American Development Bank.

8. Bussell, J. (2011). Explaining Cross-National Variation in Government Adoption of New Technologies. International Studies Quarterly, 55(1), 267-280.

9. Chourabi, H., Nam, T., Walker, S., Gil-Garcia, J. R., Mellouli, S., Nahon, K., . . . Scholl, H. J. (2012). Understanding smart cities: An integrative framework. 45th Hawaii International Conference on System Sciences (pp. 2289-2297). IEEE.

10. Clarke, R. Y. (2013). Business Strategy: IDC Government Insights' Smart City Maturity Model - Assessment and Action on the Path to Maturity.

11. Cocchia, A. (2014). Smart and Digital City: A Systematic Literature Review. In R. Dameri, \& C. Rosenthal-Sabroux, Smart City. Progress in IS (pp. 13-43). Springer, Cham.

12. Coelho, T. R., Segatto, A. P., \& Frega, J. R. (2015). Analysing ICT and development from the perspective of the capabilities approach: a study in South Brazil. The Electronic Journal of Information Systems in Developing Countries, 67(2), 1-14.

13. Deloitte. (2015). Smart cities: How rapid advances in technology are reshaping our economy and society.

14. Digital Inclusion Survey. (2018). What is Digital Inclusion? Retrieved from https://digitalinclusion.umd.edu/content/what-digital-inclusion

15. Estevez, E., Lopes, N. V., \& Janowski, T. (2016). Smart Sustainable Cities Reconnaissance Study.

16. European Parliament. (2015). ICT in the developing world. Brussels.

17. Gigler, B.-S. (2009). Decentralization, clientelism and Popular Participation: Is there a role for ICTs to improve local governance? International Conference on Information and Communication Technologies and Development. Doha.

18. Gigler, B.-S. (2011). Informational Capabilities'- The Missing Link for the Impact of ICT on development. The World Bank.

19. Gomez, R., \& Pather, S. (2012). ICT evaluation: Are we asking the right questions? The Electronic Journal on Information Systems in Developing Countries, 50(5), 1-14.

20. Heeks, R. (2009). The ICT4D 2.0 Manifesto: Where Next for ICTs and International Development? Manchester: Institute for Development Policy and Management.

21. Heeks, R., \& Molla, A. (2009). Impact assessment of ICT for development projects: A compendium of approaches. IDPM Development Informatics Working Papers.

22. Heeks, R., Amalia, M., Kintu, R., \& Shah, N. (2013). Inclusive Innovation: Definition, Conceptualisation and Future Research Priorities. Manchester: IDPM Development Informatics Working Papers.

23. Hollands, R. G. (2008). Will the real smart city please stand up? City, 12(3), 303320. 
24. International Telecommunications Union. (2018). ICTs for a Sustainable World \#ICT4SDG. Retrieved from https://www.itu.int/en/sustainable-world/Pages/default.aspx

25. Joia, L. A. (2004). Bridging the digital divide: some initiatives in Brazil. Electronic Government, 1(3), 300-315.

26. Joia, L. A. (2006). Inclusão digital no Brasil: um modelo heurístico de natureza dinâmica. In P. E. Martins, \& O. P. Pieranti, Estado e gestão pública: visões do Brasil contemporâneo. Rio de Janeiro: FGV Editora.

27. Joia, L. A., \& Santos, R. P. (2018). ICT equipped bank boat and the financial inclusion of the riverine population of Marajó Island in the Brazilian Amazon. Information Systems Journal, 1-46.

28. Keeley, B. (2007). Human Capital: How What You Know Shapes Your Life. OECD Insights. OECD Publishing.

29. Kleine, D. (2010). ICT4what? - using the choice framework to operationalise the capability approach to development. Journal of International Development, 22, 674692.

30. Kleine, D., \& Unwin, T. (2009). Technological Revolution, Evolution and New Dependencies: what's new about ict4d? Third World Quarterly, 30(5), 1045-1067.

31. Lee, J. H., Hancock, M. G., \& Hu, M.-C. (2014). Towards an effective framework for building smart cities: Lessons from Seoul and San Francisco. Technological Forecasting \& Social Change, 80-99.

32. Leidner, D. E., \& Kayworth, T. (2006). A review of culture in information systems research: Toward a theory of information technology culture conflict. MIS Quarterly, 30(2), 357-399.

33. Monzon, A. (2015). Smart Cities Concept and Challenges: Bases for the Assessment of Smart City Projects.

34. Nam, T., \& Pardo, T. A. (2011). Smart City as Urban Innovation: Focusing on Management, Policy, and Context. Tallinn.

35. OECD. (2009). ICTs for Development: improving policy coherence.

36. O’Grady, M., \& O’Hare, G. (2012). How Smart Is Your City? Science, 335(3), 1581-1582.

37. Pedrelli, M. (2001). Developing countries and the ICT revolution. Luxembourg: European Parliament.

38. Prahalad, C., \& Hart, S. L. (2002). The Fortune at the Bottom of the Pyramid. Strategy+Business(26).

39. Ramaprasad, A., Sánchez-Ortiz, A., \& Syn, T. (2017). A Unified Definition of a Smart City. 16th IFIP WG 8.5 International Conference (pp. 13-24). St. Petersburg: Electronic Government.

40. Repko, J., \& De Broux, S. (2012). Smart Cities Literature Review and Analysis. Emerging Trends in Information Technology.

41. Sen, A. (1979). Equality of What? Tanner Lectures on Human Values.

42. Sen, A. (1989). Development as Capability Expansion. Journal of Development Planning, 19, 41-58.

43. Sen, A. (1999). Development as Freedom. Oxford University Press.

44. Sustainability Outlook. (2014). Shaping New Age Urban Systems: Energy, Connectivity \& Climate Resilience. 4th annual summit of the sustainable business leadership forum. New Delhi. 
45. Teles, A., \& Joia, L. A. (2011). Assessment of digital inclusion via the actornetwork theory: The case of the Brazilian municipality of Piraí. Telematics and Informatics, 28, 191-203.

46. United Nations. (2008). World Urbanization Prospects: The 2007 Revision. New York.

47. United Nations. (2015, September 25). Transforming our world: the 2030 Agenda for Sustainable Development.

48. United Nations Economic and Social Council. (2006). Fourth annual report of the Information and Communication Technologies Task Force. .

49. Warschauer, M. (2003). Technology and Social Inclusion: Rethinking the Digital 